\title{
Usefulness of Betalactam Therapy for Community-Acquired Pneumonia in the Era of Drug-Resistant Streptococcus pneumoniae: A Randomized Study of Amoxicillin-Clavulanate and Ceftriaxone
}

\author{
BEATRIZ ROSÓN, ${ }^{1}$ JORDI CARRATALÀ, ${ }^{1}$ FE TUBAU,${ }^{2}$ JORDI DORCA,${ }^{3}$ JOSEFINA LIÑARES, ${ }^{2}$ \\ ROMAN PALLARES, ${ }^{1}$ FREDERIC MANRESA, ${ }^{3}$ and FRANCESC GUDIOL ${ }^{1}$
}

\begin{abstract}
Empirical antibiotic therapy of community-acquired pneumonia (CAP) has been complicated by the worldwide emergence of penicillin resistance among Streptococcus pneumoniae. The impact of this resistance on the outcome of patients hospitalized for CAP, empirically treated with betalactams, has not been evaluated in a randomized study. We conducted a prospective, randomized trial to assess the efficacy of amoxicillin-clavulanate $(2 \mathrm{~g} / 200 \mathrm{mg} / 8 \mathrm{hr})$ and ceftriaxone $(1 \mathrm{~g} / 24 \mathrm{hr})$ in a cohort of patients hospitalized for moderate-to-severe CAP. Three-hundred seventy-eight patients were randomized to receive amoxicillin-clavulanate (184 patients) or ceftriaxone (194 patients). Efficacy was assessed on Day 2, after completion of therapy and at long term follow-up. There were no significant differences in outcomes between treatment groups, both in intention-to-treat and per-protocol analysis. Overall mortality was $10.3 \%$ for amoxicillin-clavulanate and $8.8 \%$ for ceftriaxone (NS). There were 116 evaluable patients with proven pneumococcal pneumonia. Rates of highlevel penicillin resistance (MIC of penicillin $\geq 2 \mu \mathrm{g} / \mathrm{mL}$ ) were similar in the two groups $(8.2$ and $10.2 \%$ ). Clinical efficacy at the end of therapy was $90.6 \%$ for amoxicillin-clavulanate and $88.9 \%$ for ceftriaxone $(95 \%$ C.I. of the difference: -9.3 to $+\mathbf{1 2 . 7 \%}$ ). No differences in outcomes were attributable to differences in penicillin susceptibility of pneumococcal strains. Sequential i.v./oral amoxicillin-clavulanate and parenteral ceftriaxone were equally safe and effective for the empirical treatment of acute bacterial pneumonia, including penicillin and cephalosporin-resistant pneumococcal pneumonia. The use of appropriate betalactams in patients with penumococcal pneumonia and in the overall CAP population, is reliable at the current level of resistance.
\end{abstract}

\section{INTRODUCTION}

$\mathbf{E}$ MPIRICAL ANTIBIOTIC THERAPY of community-acquired pneumonia (CAP) is a controversial medical topic today. ${ }^{3,14}$ This is largely due to the worldwide emergence of antibiotic resistance among Streptococcus pneumoniae, which remains the most frequent cause of CAP requiring hospitalization. $^{2,7,25}$ One of the main issues regarding CAP therapy is whether or not betalactams can be used successfully against betalactam-resistant pneumococci. In a previous, nonrandomized study, we have shown that intravenous high-dose penicillin and some expanded-spectrumcephalosporins were effective for the treatment of pneumococcal pneumonia caused by strains with minimal inhibitory concentrations (MICs) up to $2 \mu \mathrm{g} / \mathrm{mL}^{29}$
However, the MICs of penicillins and cephalosporins above which therapeutic failures would be expected are not known. ${ }^{18}$ In addition, the impact of penicillin resistance on the outcome of a large cohort of patients with CAP receiving empirical betalactam therapy has not been evaluated prospectively. Most authorities do recommend third-generation cephalosporins or betalactam-betalactamase inhibitors as the first line therapy for hospitalized CAP, but suggest the use of alternative drugs such as vancomycin or fluoroquinolones for strains resistant to penicillin (MIC $\geq 2 \mu \mathrm{g} / \mathrm{mL}$ ), or as empirical therapy in critically ill patients; however these suggestions are based on 'in vitro' data, and firm recommendations must await additional controlled studies. ${ }^{1,3,16,32}$

To address these issues in an area with high prevalence of

From the ${ }^{1}$ Infectious Disease, ${ }^{2}$ Microbiology, and ${ }^{3}$ Respiratory Services, Ciutat Sanitària i Universitària de Bellvitge, University of Barcelona, L'Hospitalet de Llobregat, Barcelona, Spain. 
antibiotic-resistant pneumococci, we performed a randomized trial, comparing two commonly used betalactam agents in the treatment of moderate-to-severe CAP: amoxicillin-clavulanate and ceftriaxone. MICs of both antibiotics against resistant pneumococci are usually lower than that of penicillin $G$ and their broad-spectrum makes them safe enough for empirical therapy of CAP of presumed bacterial etiology. ${ }^{23,33}$

\section{PATIENTS AND METHODS}

\section{Study design}

The design was conducted at Bellvitge Hospital, a 1000-bed University hospital in Barcelona, Spain, which serves an area of 1,100,000 inhabitants. It was comparative, prospective, randomized, and assessor-blindedin early assessments. All patients included gave informed consent to enter, and the study was approved by the Ethical Committee at our institution.

\section{Patient eligibility}

All nonimmunosuppressed adult patients with moderate-tosevere CAP who were admitted to the hospital from February 1995 through May 1997 were considered for study inclusion. Patients were excluded if they met one or more of the following criteria: unwillingness to enter the study; age $\leq 16$ years; hypersensitivity to $\beta$-lactam antibiotics; pregnancy or breastfeeding; immunosuppression (AIDS, end-stage neoplasia, cytotoxic therapy, absolute neutropenia, or transplantation); shock unresponsive to therapy; concomitant endocarditis or meningitis; high clinical suspicion of Legionella, atypical, viral or aspiration pneumonia; previous antibiotic therapy for more than $24 \mathrm{~h}$; and previous hospitalization within the past 14 days.

\section{Randomization}

Eligible patients were randomized by the infectious disease consultant, who opened sealed, sequentially numbered envelopes. Random blocks of 25 allocations equally divided between regimens were used. Patients were assigned to receive either i.v. amoxicillin-clavulanate ( $2 \mathrm{~g} / 200 \mathrm{mg}$ every $8 \mathrm{hr}$ ) or i.v. ceftriaxone ( $1 \mathrm{~g}$ every $24 \mathrm{hr}$ ) for at least $72 \mathrm{hr}$. After a significant clinical improvement was achieved, sequential oral amoxicillin-clavulanate $(1 \mathrm{~g} / 125 \mathrm{mg}$ every $8 \mathrm{hr})$ or i.m. ceftriaxone ( $1 \mathrm{~g}$ every $24 \mathrm{hr}$ ) were initiated. The addition of intravenous erythromycin at randomization was allowed if indicated by the attending physician. No other antibiotic therapy was permitted during the study period. All medication was provided by the hospital pharmacy.

\section{Definitions}

CAP was defined as an acute respiratory illness associated with one or more of the following: fever or hypothermia, cough, sputum production, pleuritic chest pain, dyspnea, altered breath sounds on auscultation; plus the presence of a new infiltrate on a chest radiograph. CAP was considered moderate-to-severe when one or more of the following criteria was present: age $\geq 70$ years; $\mathrm{PaO}_{2}<60 \mathrm{mmHg}$ or $\mathrm{PaO}_{2} / \mathrm{FiO}_{2}<300$; multilobar radiological involvement; hypotension or shock; and underlying disease such as alcoholism, chronic obstructive pulmonary disease (COPD), congestive heart failure, renal failure, splenectomy and diabetes mellitus. The simplified acute physiology score (SAPS) was applied as described elsewhere. ${ }^{19}$ To stratify patients in risk classes we used the validated prediction rule calculated according to the Pneumonia Severity Index (PSI) scores, developed by the Pneumonia Outcomes Research Team as described elsewhere. ${ }^{11}$ Overall mortality was defined as death by any cause within 30 days of hospitalization.

Etiological diagnosis of CAP was considered definitive when there was: isolation of a respiratory pathogen from a normally sterile specimen; isolation of L. pneumophila or Mycobacterium tuberculosis from sputum; detection of pneumococcal antigens by latex agglutination or pneumococcal DNA by polymerase chain reaction (PCR) in pleural fluid or transthoracic needle aspiration (TNA) specimens; detection of L. pneumophila serogroup 1 antigen in urine; four-fold increase in the antibody titre or seroconversion for Mycoplasma pneumoniae, Chlamydia psittaci, Chlamydia pneumoniae, Coxiella burnetii, L. pneumophila, respiratory syncytial virus, influenza A virus and parainfluenza 3 virus. Etiological diagnosis was considered presumptive when a predominant microorganism that correlated with a predominant morphotype in the Gram stain was isolated from sputum samples of good quality [presence of $>25$ polymorphonuclear leukocytes and $<10$ squamous cells per lowmagnification field $(\times 10]$. Presumptive aspiration pneumonia (anaerobic infection) was diagnosed on a clinical and radiological basis, in patients with specific risk factors. The remaining cases were considered as pneumonia of unknown etiology.

\section{Clinical and bacteriological evaluation}

At the initial visit and before starting antibiotic therapy, each patient underwent a complete history and physical examination. Chest radiographs, arterial blood gas determinations, and basic chemistry and hematology tests were performed. Two sets of blood cultures were drawn and a sputum sample was processed for Gram stain and culture if available. Invasive procedures such as bronchoscopy or TNA were performed if indicated by the attending physician.

Follow-up visits were performed daily during hospital stay. Chest radiographs, hematology and chemistry tests, and repeated sputum cultures, if obtainable, were performed on Day 2 , at the end of study and at the long-term follow-up visit, approximately 1 month after discharge. Blood cultures were repeated at $48 \mathrm{hr}$ if initially positive, and when clinically indicated.

\section{Microbiological studies}

Investigation of pathogens in blood, normally sterile fluids, sputum and TNA samples and serological studies were performed by standard microbiological procedures. Latex agglutination and PCR detection of S. pneumoniae was performed in TNA samples as described elsewhere. ${ }^{13}$ Detection of L. pneumophila serogroup I antigen in urine was performed by an immunoenzymatic commercial method (Legionella Urinary Antigen, Binax, Portland, ME). 
Susceptibility tests in $H$. influenzae strains were performed by a microdilution method with Haemophilus test medium, as described in NCCLS standards. ${ }^{27}$ Detection of betalactamase production was performed by using a commercial chromogenic cephalosporintest (Nitrocefin; Cefinase; Becton Dickinson Microbiology Systems, Cockeysville, MD).

Susceptibility tests of $S$. pneumoniae strains were performed by a microdilution method with Mueller-Hinton broth $\left(\mathrm{Ca}^{++}\right.$ and $\mathrm{Mg}^{++}$cation-adjusted) supplemented with 5\% lysed horse blood, as described in NCCLS standards. ${ }^{27}$ The antibiotics tested were: penicillin, amoxicillin-clavulanate, ceftriaxone, erythromycin, clindamycin, tetracycline, chloramphenicol, and trimethoprim-sulfamethoxazole. MIC was defined as the lowest concentration of antimicrobial that prevented visible growth after an overnight incubation of plates at $35^{\circ} \mathrm{C}$. Resistance to antimicrobial agents was defined according to the NCCLS criteria. ${ }^{26}$ Serotyping of pneumococcal strains was performed at the Spanish Pneumococcal Reference Laboratory (Majadahonda, Madrid) by detecting the quellung reaction with use of 46 antisera provided by the Staten Seruminstitut (Copenhaguen).

\section{Assessment of efficacy}

Clinical efficacy was assessed three times during follow-up. The first evaluation, "early assessment," took place on Day 2. Two experienced clinical investigators (F.M. and F.G., in most cases), who were blind to the treatment regimen, classified the response as: (1) improvement, when the acute symptoms had clearly regressed; (2) failure, in any of the following circumstances: no apparent clinical response to therapy, septic metastases, previously unrecognised shock or hemodynamic failure, worsening of respiratory failure, radiological progression, or severe adverse events; and (3) indeterminate, when improvement was insufficient. In these cases, a new clinical evaluation was performed $24 \mathrm{hr}$ later and the case was definitively classified as failure or improvement.

The second evaluation, "end of therapy assessment," was performed 24-48 hr after completion of therapy. Cases were classified as: (1) cure, when clinical findings of pneumonia had disappeared and there was radiological improvement; (2) failure, under the following circumstances: lack of improvement, superinfection, inability to complete treatment due to adverse events, or death by any cause.

The third evaluation, "final assessment," was performed at the long-term follow-up visit. Cases were classified as: (1) cure, when there was clinical and radiological resolution; (2) failure, when there was persistence or recrudescence of symptoms, or any case previously classified as failure; and (3) unevaluable per protocol analysis, when a noninfectious cause of pulmonary infiltrates was documented, or if patients did not attend the follow-up visit. Assessment of health status of all patients not attending the visit was attempted by telephone contact.

Only culture-positive pneumonias were considered for bacteriological evaluation, which was performed three times during follow-up: at $48 \mathrm{hr}$ of therapy, after completion of treatment, and at the long-term follow-up visit. Response was classified as satisfactory if there was eradication of the microorganism or if respiratory samples could not be obtained due to improvement; unsatisfactory, if the previously identified pathogen was still isolated, or when superinfection requiring additional antimicrobial therapy occurred; and indeterminate, when the evaluation could not be performed for any reason.

\section{Statistical analysis}

The trial was designed under the hypothesis that clinical cure rate would be equivalent in the treatment groups. The sample size was determined in order to detect a $15 \%$ difference in the clinical cure rate for pneumococcal pneumonia, if the expected clinical cure rate using parenteral ceftriaxone in patients with moderate-to-severe pneumococcal pneumonia was $80 \%$. With a power of $80 \%$ [type II error $(\beta)=0.20$ ] and using a twosided $95 \%$ confidence interval [type I error $(\alpha)=0.05$ ], 75 evaluable patients per treatment group were required. Considering that $S$. pneumoniae would cause around $50 \%$ of moderate-to-severe bacterial CAP, and allowing for $15 \%$ unevaluability, a total of 345 patients was needed.

Comparisons between groups were performed by a $\chi^{2}$ test with continuity correction or an independent sample $t$-test, when appropriate. Significance was defined at a $P$ value $<0.05$ using a two-sided test.

For assessment of clinical efficacy, two analyses were performed: an intention-to-treatanalysis, including all randomized patients, and a per protocol analysis of all evaluable patients. Special emphasis was placed on the assessment of response in proven pneumococcal pneumonia, with subanalysis of penicillin-resistant cases. A two-sided $95 \%$ confidence interval was calculated for the difference in success rates between the two treatment groups.

\section{RESULTS}

\section{Trial profile}

Of the 543 patients who were considered for inclusion during the study period, 378 were finally randomized to receive amoxicillin-clavulanate (184 patients) or ceftriaxone (194 patients) and analyzed by intention-to-treat. After excluding 55 additional unevaluable patients, the remaining 323 were considered evaluable and analyzed per protocol. Figure 1 illustrates the trial profile. We kept a book log with the diagnosis and outcome of all nonrandomized patients.

\section{Characteristics of patients}

Table 1 shows the baseline characteristics of the 378 randomized patients. There were no differences between treatment groups, including the distribution of most significant underlying diseases, such as cancer, COPD, chronic heart disease, and diabetes mellitus. Baseline characteristics of the 323 evaluable patients and the 115 patients with proven pneumococcal pneumonia were also similar.

\section{Etiology}

Table 2 shows the distribution of causative organisms of the 323 evaluable cases, in both treatment groups. In $83(52.9 \%)$ pneumonias of the amoxicillin-clavulanate group and 86 


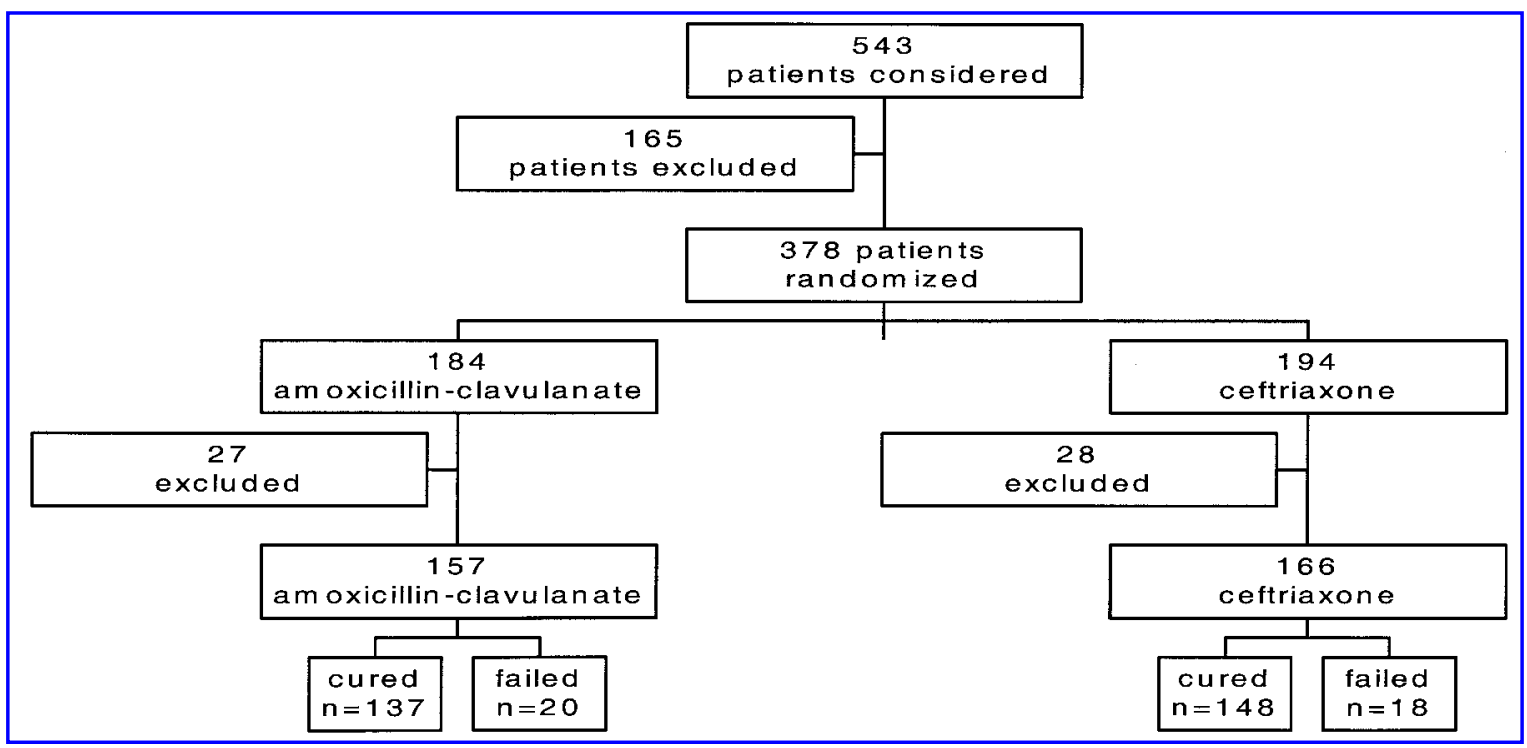

FIG. 1. Trial profile.

(51.8\%) of the ceftriaxone group no pathogens were identified. Overall, S. pneumoniae was the most frequently identified causative agent, accounting for 71.6 and $78.7 \%$ of pneumonias with a proven etiology respectively, and $34.9 \%$ of the total illnesses included in the study.

\section{Antibiotic therapy}

Mean duration of i.v. therapy was 5.4 days for the amoxicillin-clavulanate group and 5.3 days for the ceftriaxone group $(p=0.63)$. Complete duration of antibiotic therapy was 10.9 days and 10.1 days, respectively $(p=0.18)$. Seventeen patients $(9.2 \%)$ in the amoxicillin-clavulanate group and 25 patients
(12.9\%) in the ceftriaxone group initially received combination erythromycin therapy. Seven patients with proven pneumococcal pneumonia ( 2 and 5, respectively) received combination therapy with erythromycin. In five of them the diagnosis was performed by isolation of $S$. pneumoniae. Four of these strains were fully sensitive to penicillin (MIC $<0.03 \mu \mathrm{g} / \mathrm{mL}$ ) and the remaining had an MIC of $2 \mu \mathrm{g} / \mathrm{mL}$.

\section{Intention-to-treat analysis}

Patients were hospitalized for a mean of 10.7 days in the amoxicillin-clavulanate group and 11.3 days in the ceftriaxone group. Fourteen patients in each group required intensive care

Table 1. Baseline Characteristics of All Randomized Patients

\begin{tabular}{|c|c|c|}
\hline Characteristic & $\begin{array}{c}\text { Amoxicillin-clavulanate } \\
\text { No. }(\%)\end{array}$ & $\begin{array}{c}\text { Ceftriaxone } \\
\text { No. }(\%)\end{array}$ \\
\hline Patients & 184 & 194 \\
\hline Age, y (mean) & 66 & 67 \\
\hline Sex (male/female) & $123 / 61$ & $144 / 50$ \\
\hline Underlying disease & $130(70.7)$ & $147(75.8)$ \\
\hline Previous antibiotic therapy & $35(19.0)$ & $35(18.0)$ \\
\hline Influenza vaccine & $75(40.8)$ & $96(49.5)$ \\
\hline Pneumococcal vaccine & $10(5.4)$ & $5(2.6)$ \\
\hline Impaired consciousness & $19(10.3)$ & $26(13.4)$ \\
\hline Multilobar infiltrate & $52(28.3)$ & $62(32.0)$ \\
\hline Shock at onset & $7(3.8)$ & $5(2.5)$ \\
\hline PSI classes (IV-V) & $110(59.8)$ & $113(58.2)$ \\
\hline SAPS (mean) & 9.4 & 9.4 \\
\hline Axillary temperature (mean) ${ }^{\circ} \mathrm{C}$ & 38.2 & 38.2 \\
\hline Respiratory rate per min (mean) & 29 & 30 \\
\hline $\mathrm{PO}_{2} / \mathrm{FiO}_{2}$ (mean) & 274 & 270 \\
\hline Empyema & $10(5.4)$ & $11(5.7)$ \\
\hline Bacteremia & $20(10.9)$ & $26(13.4)$ \\
\hline
\end{tabular}

No differences were statistically significant. SAPS, Simplified acute physiology score; and PSI, pneumonia severity index. 
Table 2. Distribution of Causative Agents in 323 Evaluable

Patients with Community-Acquired Pneumonia According to Treatment Groups

\begin{tabular}{lcc}
\hline Causative agents $^{\mathrm{a}}$ & Amoxicillin-clavulanate & Ceftriaxone $^{-}$ \\
\hline Patients & 157 & 166 \\
Streptococcus pneumoniae & 53 & 63 \\
Haemophilus influenzae & 15 & 13 \\
Moraxella catarrhalis & 3 & 3 \\
Enterobacteriaceae & 1 & 3 \\
Others & 5 & 1 \\
Atypical agents & 4 & 5 \\
No pathogen identified & $83(52.9 \%)$ & $86(51.8 \%)$ \\
\hline
\end{tabular}

${ }^{\text {a }}$ The sum is more than 323 because fifteen patients had mixed infections (7 in amoxicillin-clavulanate group and 8 in ceftriaxone group).

${ }^{b}$ All of these patients had mixed infections.

unit (ICU) admission and most of them underwent mechanical ventilation (10 and 10). In-hospital complications were observed in $51(27.7 \%)$ and $54(27.8 \%)$ patients, respectively, the most frequent being congestive heart failure (10 and 9), and pleural empyema (10 and 11).

As shown in Table 3, there were no significant differences in clinical efficacy between the two treatment groups in any of the three assessments. In the final assessment, the success rates were 73.9 and $74.2 \%$, respectively. Overall mortality was similar among patients receiving amoxicillin-clavulanate $(10.3 \%)$ and those receiving ceftriaxone $(8.8 \%)$.

Both drugs were well tolerated, and most adverse events were mild; only two patients stopped treatment due to adverse events. Forty-one patients $(22.2 \%)$ in the amoxicillin-clavulanate group and 34 patients $(17.5 \%)$ in the ceftriaxone group presented drugrelated adverse events, the most frequent being phlebitis (30 and 25) and gastrointestinal discomfort (9 and 2).

\section{Patients excluded after randomization}

Fifty-five patients were excluded from the per protocol analysis, 27 in the amoxicillin-clavulanate group and 28 in the ceftriaxone group. Most had noninfectiouspulmonary infiltrates or atypical or Legionella pneumonia. Table 4 shows causes of exclusion and mortality of these patients.

\section{Per protocol analysis}

One hundred and fifty-seven patients in the amoxicillinclavulanate group and 166 in the ceftriaxone group were evaluable per protocol. Nine and 11 patients, respectively, were not assessable at the long-term follow-up visit ( 3 and 5 patients in good health refused to attend the visit, 3 and 4 patients died for cause unrelated to infection, 2 and 2 patients could not be located, and AIDS was diagnosed in one patient in the amoxicillin-clavulanate group). As shown in Table 3, there were no differences in clinical efficacy and mortality between groups. Overall, 38 patients had an unsatisfactory response throughout the study. Criteria for considering these patients as failures are summarized in Table 5. Bacteriological efficacy, assessed in 137 cases, was 92.4 and $95.8 \%$, respectively.

\section{Antibiotic susceptibilities and pneumoccal serogroups/types}

Overall, $88.9 \%$ of the isolated pathogens were susceptible to amoxicillin-clavulanate, and $89.6 \%$ were susceptible to ceftriaxone. Susceptibilities of $105 \mathrm{~S}$. pneumoniae strains are shown in Table 6. There were four $(3.8 \%)$ strains of pneumococci with penicillin MICs of $4 \mu \mathrm{g} / \mathrm{mL}$, and $11(10.5 \%)$ strains showed multiple-resistance. MICs of amoxicillin (and amoxicillinclavulanate) and ceftriaxone were similar, ranging from 0.015 to $2 \mu \mathrm{g} / \mathrm{mL}$. Five strains showed a MIC of $2 \mu \mathrm{g} / \mathrm{mL}$ for amoxicillin ( 2 in the amoxicillin-clavulanate group and 3 in the ceftriaxone group) and four strains had a MIC of $2 \mu \mathrm{g} / \mathrm{mL}$ for ceftriaxone (2 and 2). Twenty-two different serogroups/types (SGT) were found among the 105 pneumococci isolates. Eight SGT accounted $79.8 \%$ of strains $(83 / 105)$. The more frequent SGT were: 3 (34.3\%); 8 (11.4\%); 4 (7.6\%); 19 (6.7\%); 14 (5.7\%); $9(5.7 \%) ; 23(4.8 \%)$, and $6(2.9 \%)$.

Among the $28 \mathrm{H}$. influenzae isolates, $\beta$-lactamase production was detected in $17.9 \%$ of strains and no strain was resistant to the study drugs.

\section{Pneumococcal pneumonia}

There were 116 evaluate patients with proved pneumococcal pneumonia; 53 received amoxicillin-clavulanate and 63 ceftriaxone. Rates of high-level penicillin resistance were similar (8.2 and $10.2 \%$ ). Table 7 shows treatment and outcomes of these patients. There were seven early clinical failures (four amoxicillin-clavulanate and three ceftriaxone), none of them presumably related to antibiotic resistance. Clinical efficacy at the end of therapy was 90.6 and $88.9 \%$, respectively (95\% C.I. of the difference, $-9.3 \%$ to $+12.7 \%$ ). Mortality at 30 days was 9.4 and $11.1 \%$, respectively. A satisfactory outcome at the end of therapy was observed in $76(90.5 \%)$ of patients with penicillin-susceptible strains and in $18(85.7 \%)$ of patients with penicillin-resistant strains $(p=0.81)$. No relapses were observed at long-term follow-up. A detailed analysis of patients with pneumococcal pneumonia who were classified as failures at any assessment is provided in Table 8 .

Among patients receiving amoxicillin-clavulanate, a satis- 


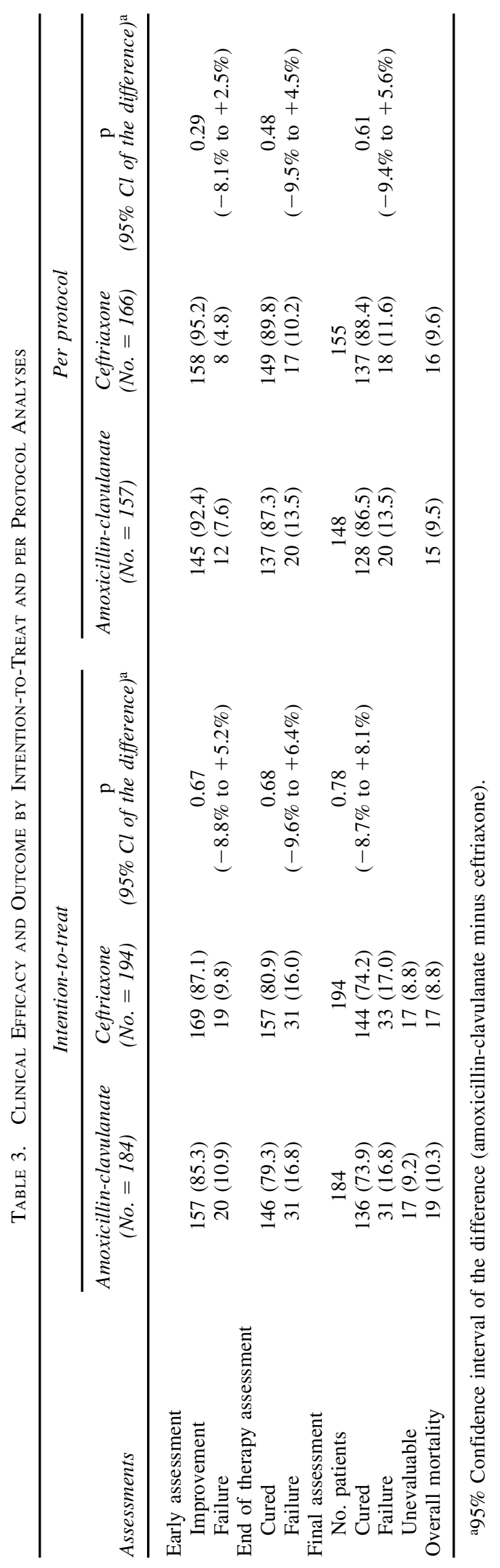


Table 4. Patients Excluded after Randomization:

Causes and Outcome

\begin{tabular}{lcc}
\hline Causes of exclusion & Amoxicillin-clavulanate & Ceftriaxone \\
\hline No. of patients & 27 & 28 \\
Misrandomization & 10 & 8 \\
$\quad$ No pneumonia & 7 & 5 \\
No severity criteria & 3 & - \\
AIDS & - & 2 \\
Unresponsive shock & - & 1 \\
Protocol violation & 3 & 7 \\
Atypical agents & 11 & 11 \\
$\quad$ Legionella & 4 & 3 \\
Atypical & 6 & 5 \\
Others & 1 & 3 \\
Aspiration pneumonia & 3 & 2 \\
Overall mortality & 4 & 1 \\
\hline
\end{tabular}

factory outcome at the end of therapy was observed in 39 $(88.6 \%)$ of amoxicillin-susceptible strains and in $5(100 \%)$ of amoxicillin-resistant strains $(p=0.98)$. Among patients receiving ceftriaxone, a satisfactory outcome at the end of therapy was observed in $44(91.7 \%)$ of cephalosporin-susceptible strains and in $6(75.0 \%)$ of cephalosporin-resistant strains $(p=$ 0.42).

\section{DISCUSSION}

The worldwide emergence of penicillin resistance among Streptococcus pneumoniae has complicated the treatment of pneumococcal pneumonia and, consequently, the empirical therapy of the entire group of patients with suspected bacterial CAP. To date, the clinical relevance of "in vitro" resistance to betalactams in these infections is unclear and there is no universally accepted "gold standard" for the treatment of resistant pneumococcal pneumonia $(16,18,32)$. In this randomized trial evaluating a large population of patients with CAP who fulfilled previously defined hospitalization criteria, amoxicillinclavulanate and cefriaxone were found to be equally safe and effective. Rates of failure and mortality were in the low range of those reported for moderate-to-severe CAP, both in the total group of patients and in the subset of patients with proven pneumococcal pneumonia..$^{1,12,38}$ We also found no significant difference in outcomes attributable to penicillin susceptibility of pneumococcal strains and no differences attributable to treatment regimens in penicillin and cephalosporin-resistant pneumococcal pneumonia. Nevertheless, when interpreting our findings it should be kept in mind the small number of highly resistant strains isolated in our trial.

Our data are useful for assessing the efficacy of betalactam therapy for CAP of suspected bacterial etiology, in an area of high prevalence of penicillin-resistant pneumococci, especially taking into account that only a low proportion of patients re-

Table 5. Causes of Failure in Evaluable Patients According to Treatment Group

\begin{tabular}{lcc}
\hline Cause of failure & Amoxicillin-clavulanate & Ceftriaxone \\
\hline No. of patients & 20 & 18 \\
Early assessment & 12 & 8 \\
$\quad$ Died before assessment & 7 & 4 \\
No improvement & 2 & - \\
Clinical worsening & 3 & 4 \\
$\quad$ Acute respiratory failure & 3 & 4 \\
$\quad$ Hemodynamic failure & - & 2 \\
$\quad$ Radiological progression & 2 & 3 \\
End of therapy assessment & 8 & 9 \\
Superinfection & 2 & 2 \\
Adverse effects & 1 & 1 \\
Change of therapy & 1 & 6 \\
Death & 4 & 2 \\
$\quad$ Pneumonia related & 3 & 4 \\
$\quad$ Nonrelated to pneumonia & 1 & 1 \\
Final assessment & - & 1 \\
Superinfection & - & 6 \\
\hline
\end{tabular}




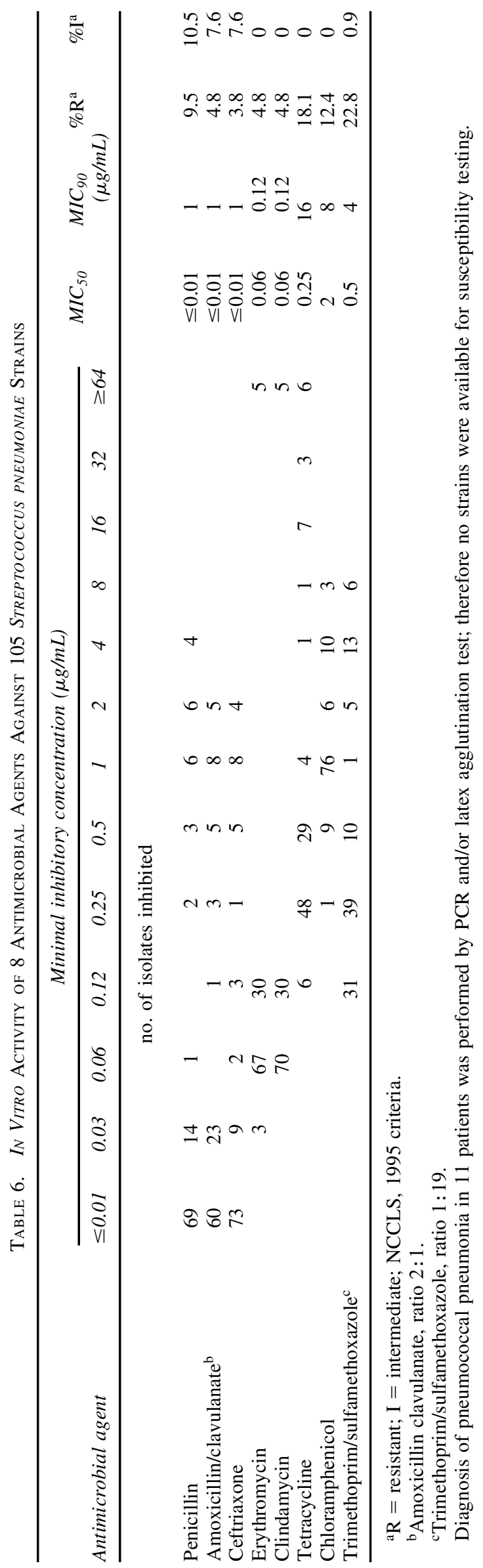


Table 7. Treatment and Outcomes of 116 Patients with Pneumococcal Pneumonia

\begin{tabular}{|c|c|c|}
\hline Outcomes & $\begin{array}{c}\text { Amoxicillin-clavulanate } \\
\mathrm{n}(\%)\end{array}$ & $\begin{array}{l}\text { Ceftriaxone } \\
\mathrm{n}(\%)\end{array}$ \\
\hline Patient nos. & 53 & 63 \\
\hline \multicolumn{3}{|l|}{ Length of therapy (mean \pm SD) } \\
\hline intravenous & $5.5 \pm 1.6$ & $6.2 \pm 3.7$ \\
\hline complete & $11.8 \pm 9.9$ & $11.8 \pm 5.7$ \\
\hline Combination macrolide therapy & $2(3.8)$ & $5(7.9)$ \\
\hline Mechanical ventilation & $2(3.8)$ & $3(4.8)$ \\
\hline Time to defervescence $\left(\mathrm{T} \leq 37.0^{\circ} \mathrm{C}\right)($ mean $\pm \mathrm{SD})$ & $2.6 \pm 2.2$ & $2.8 \pm 3.6$ \\
\hline Length of hospital stay (mean \pm SD) & $9.5 \pm 5.0$ & $12.7 \pm 13.0$ \\
\hline Adverse events & $12(22.6)$ & $11(17.5)$ \\
\hline Overall mortality & $5(9.4)$ & $7(11.1)$ \\
\hline early death $<48 \mathrm{~h}$ & $3(5.7)$ & $2(3.2)$ \\
\hline Clinical efficacy ${ }^{\mathrm{a}}$ (success/total) & $48 / 53$ & $56 / 63$ \\
\hline bacteremic & $12 / 14$ & $16 / 20$ \\
\hline \multicolumn{3}{|l|}{ MIC of penicillin } \\
\hline$\leq 0.06 \mu \mathrm{g} / \mathrm{mL}$ & $37 / 42$ & $39 / 42$ \\
\hline$\geq 0.12-1 \mu \mathrm{g} / \mathrm{mL}$ & $3 / 3$ & $7 / 8$ \\
\hline $2 \mu \mathrm{g} / \mathrm{mL}$ & $4 / 4$ & $4 / 6$ \\
\hline Bacteriological efficacy ${ }^{\mathrm{b}}$ (success/total) & $45 / 46$ & $52 / 53$ \\
\hline
\end{tabular}

Baseline clinical characteristics were similar in the two groups. No differences were statistically significant.

${ }^{a}$ At the end of therapy.

${ }^{\mathrm{b}}$ Two failures due to superinfection.

ceived combination macrolide therapy. Our data show that both amoxicillin-clavulanate and ceftriaxone can be used against pneumococci with penicillin MICs of $4 \mu \mathrm{g} / \mathrm{mL}$. This finding may be relevant for future recommendations, because a substantial number of pneumococci isolated from patients with CAP have penicillin MICs between 1 and $4 \mu \mathrm{g} / \mathrm{mL}$, and it is very unusual to isolate strains with higher MICs. ${ }^{8,21,24,34}$ In our country, penicillin resistance increased dramatically during the 1980 s, but it has remained stable since then. A recent nationwide survey reported a resistance rate of approximately $40 \%$ while cephalosporin resistance is increasing slightly., ${ }^{9,20}$ In some European countries and the United States, with lower figures, there has been a marked increase in the prevalence of drug resistance in the 1990s, similar to the rise recorded in Spain in the previous decade. ${ }^{6,37}$ On the other hand, the level of resistance also appears to remain stable or to increase very slowly, and currently it is very rare to isolate pneumococcal strains with ceftriaxone MICs higher than $2 \mu \mathrm{g} / \mathrm{mL}$. The frequency of these strains has been reported to be less than $0.5 \%$ in Spain, ${ }^{8}$ and we did not identify any in this trial. Nevertheless, the importance of monitoring continuously the sensitivities of pneumococcal isolates should be stressed because the proportion of highly resistant strains may increase in the future.

In our study, the response to betalactam therapy did not differ between patients with pneumococcal pneumonia due to resistant strains and patients with susceptible strains. Although the more frequent isolation of highly resistant strains might have strengthened our conclusions, our findings, involving adult patients, are in concordance with two recent retrospective studies involving pediatric patients. These studies compared the outcomes of patients with pneumococcal pneumonia due to either penicillin susceptible or resistant strains and found that children responded equally well to betalactams regadless of the penicillin susceptibility of their pneumococcal isolates. ${ }^{5,36}$ In this regard, it should be noted that the NCCLS has recently modified the criteria to define amoxicillin resistance, increasing the MIC breakpoint from 1 to $4 \mu \mathrm{g} / \mathrm{mL}$ to define intermediate susceptibility, and from $\geq 2$ to $\geq 8 \mu \mathrm{g} / \mathrm{mL}$ to define resistance. ${ }^{29}$ Nevertheless, the criteria for the extended spectrum cephalosporins have not yet been changed. ${ }^{28,29}$ Our view is that current MIC breakpoints for cephalosporin resistance should also be redefined for the treatment of nonmeningeal pneumococcal invasive disease.

The low number of highly penicillin resistant strains (MIC $\geq$ $2 \mu \mathrm{g} / \mathrm{mL}$ ) found in the study is a reasonable reflection of the real situation of the resistance among pneumococci causing CAP in our area. In fact, rates of penicillin and multiple drug resistance in this patient population were lower than those reported by us in previous studies, which also included pneumococcal isolates from different patient populations and sources. ${ }^{21,30,31}$ This difference may be explained by the fact that the present study did not include immunosuppressed patients (AIDS and cancer patients), nosocomial pneumonias, nor sputum isolates from chronic bronchitics. In addition, the distribution of SGTs found in our study differed from those found in previous studies. ${ }^{15,21}$ In fact, more than one third of the pnemococci belonged to SGT 3, followed by SGTs 8 and 4, which are usually penicillin susceptible.SGTs 19 and 23, which are associated with multiresistant patterns, were observed in frequencies similar to those in previous studies, while SGT 14, 9, and 6 were less frequently found. ${ }^{8,21}$

The concern with the poor response to betalactams may lead to frequent use of other antimicrobial agents active against resistant pneumococci, such as glycopeptides or the new fluoroquinolones. Nowadays, there is general agreement that vancomycin should be reserved as much as possible to avoid the emergence of resistance among other Gram-positive organisms. Regarding the newest fluoroquinolones, although recent clini- 


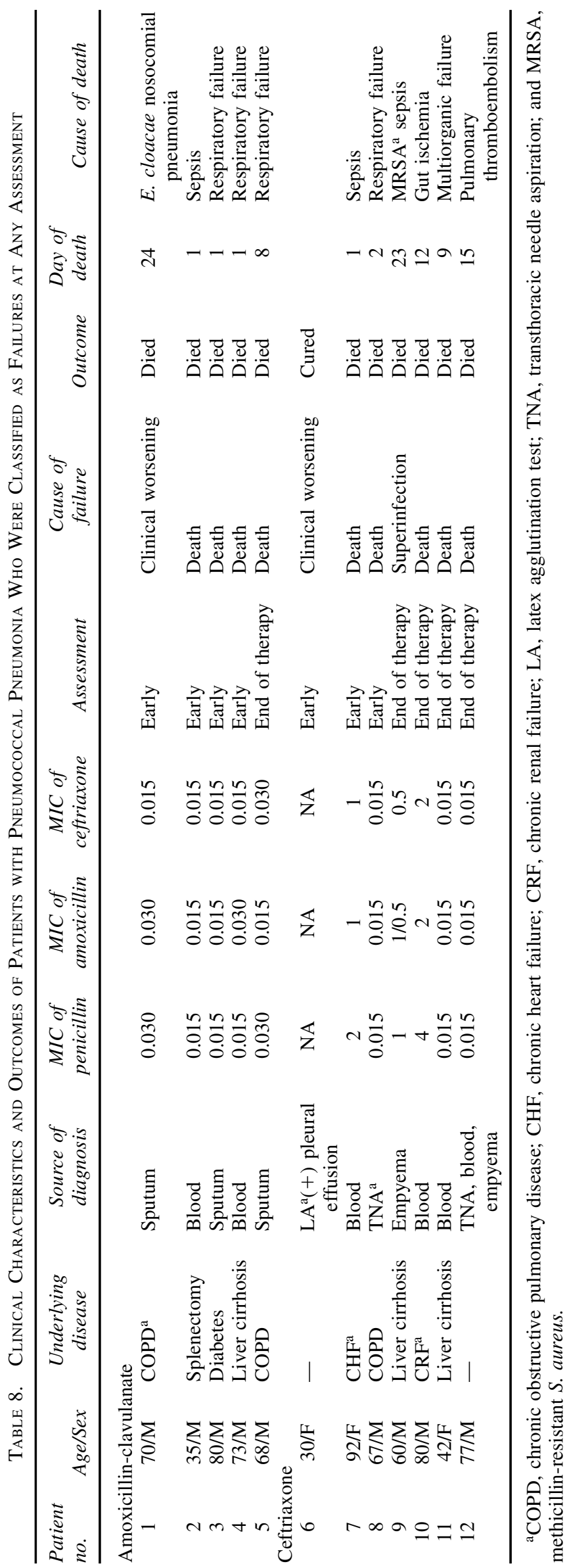


cal data support their use for the treatment of respiratory infections, ${ }^{10}$ including those due to penicillin-resistant pneumococci, controlled studies focusing on patients with severe pneumococcal pneumonia and bacteremia are still insufficient. ${ }^{17}$ In a large multicenter randomized study comparing levofloxacion with ceftriaxone/cefuroxime, File et al. ${ }^{10}$ found that levofloxacin eradicated $100 \%$ of pneumococcal isolates, although the number of bacteremic cases was very low and no penicillinresistant strain was isolated in this study. Moreover, recent data demonstrate that the prevalence of pneumococci with reduced susceptibility to fluoroquinolones is increasing in some countries, probably as a consequence of selective pressure from the increased use of fluoroquinolones. ${ }^{4}$ These data suggest prudent use of these agents, reserving them for indications where they offer a clear therapeutic advantage.,16,20 Thus, based on the current levels of resistance, physicians may feel comfortable with the continuous use of appropriate betalactams in patients with proven or suspected pneumococcal pneumonia, adding a macrolide or a fluoroquinolone when Legionella or an atypical pathogen cannot be reasonably ruled out. When choosing the most appropriate betalactam agent, it should be borne in mind that activity against penicillin-resistant pneumococci varies greatly among different betalactams and that cephalosporins with poor activity or an unfavorable pharmacodynamic profile should be avoided. ${ }^{21,33}$ In this regard it should be noted that at the dosage used of parenteral amoxicillin and ceftriaxone, the plasma levels of both antibiotics are above $8 \mu \mathrm{g} / \mathrm{mL}$ during a large percentage of the dosing interval. ${ }^{26,35}$

In conclusion, in our area where penicillin resistance is prevalent, sequential intravenous/oral amoxicillin-clavulanate and parenteral ceftriaxone were effective and safe for empirical treatment of hospitalized patients with acute bacterial pneumonia, including cases due to pneumococcal strains with penicillin MICs up to $4 \mu \mathrm{g} / \mathrm{mL}$. The use of appropriate betalactams in patients with pneumococcal pneumonia is reliable at the current level of resistance.

\section{ACKNOWLEDGMENTS}

The authors thank the staff members and residents of the Infectious Disease, Respiratory and Microbiology Services for their valuable cooperation. This study was supported in part by a grant from the Fondo de Investigaciones Sanitarias de la Seguridad Social 95/1100. B.R. is the recipient of grants from the Ciutat Sanitària i Universitària de Bellvitge 1995, Fondo de Investigaciones Sanitarias de la Seguridad Social 96/5163 and 97/5245, and Fundació Universitària Agustí Pedro i Pons 1998. This work was presented in part at the 38th Interscience Conference on Antimicrobial Agents and Chemotherapy, San Diego CA, September 1998.

\section{REFERENCES}

1. Barlett, J.G., R.F. Breiman, L.A. Mandell, and T.M. File. 1998. Community-acquired pneumonia in adults: guidelines for management. The Infectious Disease Society of America. Clin. Infect. Dis. 26:811-838.

2. Barlett, J.G., and L.M. Mundy. 1995. Community-acquired pneumonia. N. Engl. J. Med. 333:1618-1624.
3. Brown, P.D., and S.A. Lerner. 1998. Community-acquired pneumonia. Lancet. 352:1295-1302.

4. Chen, D.K., A. McGeer, J.C. de Azavedo, D.E. Low. 1999. Decreased susceptibility of Streptococcus pneumoniae to fluoroquinolones in Canada. N. Engl. J. Med. 341:233-239.

5. Deeks, S.L., R. Palacio, R. Ruvinsky, D.A. Kertesz, M. Hortal, A. Rossi, et al. 1999. Risk factors and course of illness among children with invasive penicillin-resistant Streptococcus pneumoniae. Pediatrics. 103:409-413.

6. Doern, G.V., M.A. Pfaller, K. Kluger, J. Freeman, and R.N. Jones. 1998. Prevalence of antimicrobial resistance among respiratory tract isolates of Streptococcus pneumoniae in North America: 1997 results from the SENTRY antimicrobial surveillance program. Clin. Infect. Dis. 27:764-770.

7. Fang, G.D., M. Fine, J. Orloff, D. Arismu, V.L. Yu, W. Kapoor, T. Grayston, S.P. Wang, R. Kohler, R.R. Muder, Y.C., Muder, Y.C. Muder, Y.C. Yee, J.D. Rihs, and R. M. Vickers. 1990. New and emerging etiologies for community-acquired pneumonia with implications for therapy. A prospective multicenter study of 359 cases. Medicine (Baltimore). 69:307-316.

8. Fenoll, A., I, Jado, D, Vicioso, A. Pérez, and J. Casal. 1998. Evolution of Streptococcus pneumoniae serotypes and antibiotic resistance in Spain: update (1990 to 1996). J. Clin. Microbiol. 36:3447-3454.

9. Fenoll, A., C. Martín Bourgon, R. Muñoz, D. Vicioso, and J. Casal 1991. Serotype distribution and antimicrobial resistance of Streptococcus pneumoniae isolates causing systemic infections in Spain, 1979-1989. Rev. Infect. Dis. 13:56-60.

10. File T.M., J. Sergreti, L. Dunbar, R. Player, R. Kohler, R.R. Williams, C. Kojak, and A. Rubin. 1997. A multicenter, randomized study comparing the efficacy and safety of intravenous and/or oral levofloxacion versus ceftriaxone and/or cefuroxime axetil in the treatment of adults with community-acquired pneumonia. Antimicrob. Agents Chemother. 41:1965-1972.

11. Fine, M.J., T.E. Auble, D.M. Yealy, B.H. Hanusa, L.A. Weissfeld, D.E. Singer, C.M. Coley, T.J. Marrie, and W.N. Kapoor. 1997. A prediction rule to identify low-risk patients with community-acquired pneumonia. N. Engl. J. Med. 336:243-250.

12. Fine, M.J., M.A. Smith, C.A. Carson, S.S. Mutha, S.S. Sankey, L.A. Weissfeld, and W.N. Kapoor. 1996. Prognosis and outcomes of patients with community-acquired pneumonia. A meta-analysis. JAMA. 275:134-141.

13. García, A., B. Rosón, J.L. Pérez, R. Verdaguer, J. Dorca, J. Carratalà, A. Casanova, F. Manresa, and F. Gudiol. 1999. Usefulness of PCR and antigen latex agglutination test with samples obtained by transthoracic needle aspiration for diagnosis of pneumococcal pneumonia. J. Clin. Microbiol. 37:709-714.

14. Gilbert, K., P.P. Gleason, D.E. Singer, T.J. Marrie, C.M. Coley, D.S. Obrosky, et al. 1998. Variations in antimicrobial use and cost in more than 2,000 patients with community-acquired pneumonia. Am. J. Med. 104:17-27.

15. Hausdorff, W.P., J. Bryant, C. Kloek, P.R. Paradiso, and G.R. Siber. 2000. The contribution of specific pneumococcal serogroups to different disease manifestations: Implications for conjugate vaccine formulation and use, part II. Clin. Infect. Dis. 30:122-140.

16. Heffelfinger, J.D., S.F. Dowell, J.H. Jorgensen, K.P. Klugman, L.R. Mabry, D.M. Musher, et al. 2000. Management of community-acquired pneumonia in the era of pneumococcal resistance. A report from the Drug-resistant Streptococcus pneumoniae Therapeutic Working Group. Arch. Intern. Med. 160:1399-1408.

17. Hooper, D.C. 1998. Expanding uses of fluoroquinolones: opportunities and challenges. Ann. Intern. Med. 129:908-910.

18. Kaplan, S.L., and E.O. Mason. 1998. Management of infections due to antibiotic-resistant Streptococcus pneumoniae. Clin. Microbiol. Rev. 11:628-644.

19. Le Gall, J.R., P. Loirat, A. Alpérovitch, P. Glaser, C. Granthil, D. Mathieu, P. Mercier, R. Thomas, and D. Villers. 1984. A 
Simplified Acute Physiology Score for ICU patients. Crit. Care Med. 12:975-977.

20. Liñares, J., A.G. de la Campa, R. Pallarés. 1999. Fluoroquinolone resistance in Streptococcus pneumoniae. N. Engl. J. Med. 341:1546-1547.

21. Liñares, J., F. Tubau, and M.A. Dominguez. 1999. Antibiotic resistance in Streptococcus pneumoniae in Spain: an overview of the 1990s. In A. Tomasz (ed.), Streptococcus pneumoniae: molecular biology and mechanisms of disease. Mary Ann Liebert, Inc., New York, pp. 399-409.

22. Liñares, J., T. Alonso, J.L. Pérez, J. Ayats, M.A. Dominguez, R. Pallarés, and R. Martin. 1992. Decreased susceptibility of penicillin-resistant pneumococci to twenty-four $\beta$-lactam antibiotics. J. Antimicrob. Chemother. 30:279-288.

23. Liñares, J., R. Pallares, T. Alonso, J.L. Perez, J. Ayats, F. Gudiol, P.F. Viladrich, and R. Martin. 1992. Trends in antimicrobial resistance of clinical isolates of Streptococcus pneumoniae in Bellvitge Hospital, Barcelona, Spain (1979-1990). Clin. Infect. Dis. 15:99-105.

24. Marchese, A., M. Ramirez, G.C. Schito, and A. Tomasz. 1998. Molecular epidemiology of penicillin-resistant isolates recovered in Italy from 1993 to 1996. J. Clin. Microbiol. 36:2944-2949.

25. Marrie, T.J., H. Durant, and L. Yates. 1989. Community-acquired pneumonia requiring hospitalization: 5-year prospective study. Rev. Infect. Dis. 11:586-599.

26. Martin, C., M.N. Mallet, B. Sastre, X. Viviand, A. Martin, P. De Micco, and F. Gouin. 1995. Comparison of concentrations of two doses of clavulanic acid (200 and 400 milligrams) administered with amoxicillin (2,000 milligrams) in tissues of patients undergoing colorectal surgery. Antimicrob. Agents Chemother. 39:94-98.

27. National Committee for Clinical Laboratory Standards. 1993. Methods for dilution antimicrobial susceptibility tests for bacteria that grow aerobically, 3rd ed. Approved Standard. NCCLS document M7-A3. NCCLS, 771 East Lancaster Avenue, Villanova, PA 19085, USA.

28. National Committee for Clinical Laboratory Standards. 1995. Performance Standards for Antimicrobial susceptibility testing; sixth informational supplement. NCCLS document M100-S6. NCCLS, 940 West Valley Road, Suite 1400, Wayne, PA 19087, USA.

29. National Committee for Clinical Laboratory Standards. 2000. Methods for dilution antimicrobial susceptibility tests for bacteria that grow aerobically; Approved Standard Fifth edition. NCCLS document M7-A5. Supplemental tables M100-S10. NCCLS, 940 West Valley Road, Suite 1400, Wayne, PA 19087, USA.

30. Pallarés, R., J. Liñares, M. Vadillo, C. Cabellos, F. Manresa, P.F. Viladrich, R. Martin, and F. Gudiol. 1995. Resistance to penicillin and cephalosporin and mortality from severe pneumococcal pneumonia in Barcelona, Spain. N. Engl. J. Med. 333:474480.

31. Pallarés, R., F. Gudiol, J. Liñares, J. Ariza, G. Rufí, L. Murgui, et al. 1987. Risk factors and response to antibiotic therapy in adults with bacteremic pneumonia caused by penicillin resistant pneumococci. N. Engl. J. Med. 317:18-22.

32. Pallarés R., P.F. Viladrich, J. Liñares, C. Cabellos, and F. Guidol. 1998. Impact of antibiotic resistance on chemotherapy for pneumococcal infections. Microb. Drug Resist. 4:339-347.

33. Pankuch, G.A., M.A. Visalli, M.R. Jacobs, and P.C. Appelbaum. 1995. Activities of oral and parenteral agents against penicillin-susceptible and -resistant pneumococci. Antimicrob. Agents Chemother. 39:1499-1504.

34. Rossi, A., R. Ruvinsky, M. Regueira, A. Corso, J. Pace, A. Gentile, J.L. Di Fabio, and the Streptococcus pneumoniae Working Group. 1997. Distribution of capular types and penicillin resistance of strains of Streptococcus pneumoniae causing systemic infections in Argentinian children under 5 years of age. Microb. Drug Resist. 3:135-140.

35. Scully, B.E., K.P. Fu, and H.C. Neu. 1984. Pharmacokinetics of ceftriaxone after intravenous infusion and intramuscular injection. Am. J. Med. 77:112-116.

36. Tan, T.Q., E.O. Mason, W.J. Barson, E.R. Wald, G.E. Schutze, J.S. Bradley, et al. 1998. Clinical characteristics and outcome of children with pneumonia attributable to penicillin-susceptible and penicillin non-susceptible Streptococcus pneumoniae. Pediatrics. 102:1369-1375.

37. Thornsberry, C., P. Ogilvie, J. Kahn, and Y. Mauriz. 1997. Surveillance of antimicrobial resistance in Streptococcus pneumoniae, Haemophilus influenzae, and Moraxella catarrhalis in the United States in 1996-1997 respiratory season. The Laboratory Investigator Group. Diagn. Microbiol. Infect. Dis. 29:249-257.

38. Watanakunakorn, C., and T.A. Bailey. 1997. Adult bacteremic pneumococcal pneumonia in a community teaching hospital, 1992-1996. A detailed analysis of 108 cases. Arch. Intern. Med. 157:1965-1971.

Address reprint requests to: Dr. Francesc Gudiol Infectious Disease Service Hospital de Bellvitge Feixa Llarga s/n, 08907 L'Hospitalet Barcelona, Spain

E-mail: fgudiol@csub.scs.es 


\section{This article has been cited by:}

1. N. Goffinet, N. Lecadet, M. Cousin, C. Peron, J-B. Hardouin, E. Batard, E. Montassier. 2014. Increasing use of third-generation cephalosporins for pneumonia in the emergency department: may some prescriptions be avoided?. European Journal of Clinical Microbiology \& Infectious Diseases . [CrossRef]

2. J. S. Bradley, C. L. Byington, S. S. Shah, B. Alverson, E. R. Carter, C. Harrison, S. L. Kaplan, S. E. Mace, G. H. McCracken, M. R. Moore, S. D. St Peter, J. A. Stockwell, J. T. Swanson. 2011. The Management of Community-Acquired Pneumonia in Infants and Children Older Than 3 Months of Age: Clinical Practice Guidelines by the Pediatric Infectious Diseases Society and the Infectious Diseases Society of America. Clinical Infectious Diseases 53:7, e25-e76. [CrossRef]

3. Jerónimo Pachón, Juan De Dios Alcántara Bellón, Elisa Cordero Matía, Ángela Camacho Espejo, Carmen Lama Herrera, Antonio Rivero Román. 2009. Estudio y tratamiento de las neumonías de adquisición comunitaria en adultos. Medicina Clínica 133:2, 63-73. [CrossRef]

4. H. Georges, B. Guery. 2007. Gestione delle polmoniti comunitarie in pronto soccorso. EMC - Urgenze 11:3, 1-12. [CrossRef]

5. H. Georges, B. Guery. 2007. Prise en charge des pneumonies communautaires aux urgences. EMC-Médecine $d$ 'urgence 2:1, 1-12. [CrossRef]

6. Christine CC Chiou, Victor L Yu. 2006. Severe pneumococcal pneumonia: new strategies for management. Current Opinion in Internal Medicine 5:6, 559-565. [CrossRef]

7. C. C. Chiou. 2006. Does Penicillin Remain the Drug of Choice for Pneumococcal Pneumonia in View of Emerging in Vitro Resistance?. Clinical Infectious Diseases 42:2, 234-237. [CrossRef]

8. L. R. Peterson. 2006. Penicillins for Treatment of Pneumococcal Pneumonia: Does In Vitro Resistance Really Matter?. Clinical Infectious Diseases 42:2, 224-233. [CrossRef]

9. Mark WoodheadCommunity-Acquired Pneumonia 20052652, 59-79. [CrossRef]

10. J. Garau. 2005. Role of beta-lactam agents in the treatment of community-acquired pneumonia. European Journal of Clinical Microbiology \& Infectious Diseases 24:2, 83-99. [CrossRef]

11. Pierre-Yves Bochud, Marc Bonten, Oscar Marchetti, Thierry Calandra. 2004. Antimicrobial therapy for patients with severe sepsis and septic shock: An evidence-based review. Critical Care Medicine 32:Supplement, S495-S512. [CrossRef]

12. C. D. Rothermel. 2004. Penicillin and Macrolide Resistance in Pneumococcal Pneumonia: Does In Vitro Resistance Affect Clinical Outcomes?. Clinical Infectious Diseases 38:Supplement 4, S346-S349. [CrossRef]

13. L. A. Mandell, J. G. Bartlett, S. F. Dowell, T. M. File, D. M. Musher, C. Whitney. 2003. Update of Practice Guidelines for the Management of Community-Acquired Pneumonia in Immunocompetent Adults. Clinical Infectious Diseases 37:11, 1405-1433. [CrossRef]

14. R PALLARES. 2003. The epidemiology of antibiotic resistance in Streptococcus pneumoniae and the clinical relevance of resistance to cephalosporins, macrolides and quinolones. International Journal of Antimicrobial Agents 22, 15-24. [CrossRef]

15. Jerónimo Pachón, Juan de Dios Alcántara, Elisa Cordero, Carmen Lama, Antonio Rivero. 2003. Manejo clínico de las neumonías adquiridas en la comunidad. Enfermedades Infecciosas y Microbiología Clínica 21:7, 350-357. [CrossRef]

16. Mar Marín, Francesc Gudiol. 2003. Antibióticos betalactámicos. Enfermedades Infecciosas y Microbiología Clínica 21:1, 42-55. [CrossRef]

17. V. Falcó Ferrer, A. Pahissa Berga. 2003. Tratamiento de las infecciones por neumococos resistentes a la penicilina en adultos. Revista Clínica Española 203:5, 244-247. [CrossRef]

18. Santiago Ewig, Antoni Torres. 2002. Severe community-acquired pneumonia. Current Opinion in Critical Care 8:5, 453-460. [CrossRef] 
19. Roman Pallares, Olga Capdevila, Josefina Liñares, Imma Grau, Hisao Onaga, Fe Tubau, Marco H Schulze, Peter Hohl, Francesc Gudiol. 2002. The effect of cephalosporin resistance on mortality in adult patients with nonmeningeal systemic pneumococcal infections. The American Journal of Medicine 113:2, 120-126. [CrossRef]

20. J Karlowsky. 2002. Ceftriaxone activity against Gram-positive and Gram-negative pathogens isolated in US clinical microbiology laboratories from 1996 to 2000: results from The Surveillance Network ${ }^{\circledR}$ (TSN®) Database-USA. International Journal of Antimicrobial Agents 19:5, 413-426. [CrossRef]

21. Joshua P. Metlay. 2002. Update on community-acquired pneumonia: impact of antibiotic resistance on clinical outcomes. Current Opinion in Infectious Diseases 15:2, 163-167. [CrossRef]

22. J Karlowsky. 2002. In vitro susceptibility of recent clinical isolates of pneumococci to the investigational cephalosporin cefditoren. Diagnostic Microbiology and Infectious Disease 42:1, 59-64. [CrossRef] 